\title{
Polipropilenin Eğilme Özelliklerine Geri Dönüşümlü EPDM Boyutlarının Etkisi
}

\author{
Halil Demirer $^{1}$, Yunus Tezcan ${ }^{2}$, Kenan Büyükkaya $^{3}$, İlyas Kartal ${ }^{1 *}$ \\ ${ }^{1}$ Marmara Üniversitesi, Teknoloji Fakültesi, Metalurji ve Malzeme Mühendisliği Bölümü, İstanbul, Türkiye \\ ${ }^{2}$ Marmara Üniversitesi, Fen Bilimleri Enstitüsü, Metal Eğitimi ABD, İstanbul, Türkiye \\ ${ }^{3}$ Giresun Üniversitesi, Meslek Yüksek Okulu, Makine ve Metal Teknolojileri Bölümü, Giresun, Türkiye
}

(İlk Geliş Tarihi 5 Şubat 2019 ve Kabul Tarihi 9 Mart 2019)

(DOI: $10.31590 /$ ejosat.522907)

ATIF/REFERENCE: Demirer, H., Tezcan, Y., Büyükkaya, K. \& Kartal, İ. (2019). Polipropilenin Eğilme Özelliklerine Geri Dönüşümlü EPDM Boyutlarının Etkisi. Avrupa Bilim ve Teknoloji Dergisi, (15), 381-386.

\section{$\ddot{O} \mathbf{z}$}

EPDM (etilen propilen dien monomer) önemli bir sentetik kauçuktur ve birçok farklı sektörde önemli miktarlarda kullanılır. Kullanım miktarındaki artışa paralel olarak EPDM atığı ortaya çıkmaktadır. Bu tür malzemeler, çapraz bağlanmalarından dolayı tekrar eritilip tekrar işlenme ihtimaline sahip değildir. EPDM atıkları, genellikle, ithal bazlı plastik endüstrisi için zaten önemli bir kayıp olup yakıt olarak tüketilmektedir. EPDM kalıntılarının değerlendirilmesinin bir başka yöntemi, bunları küçük boyutlara getirerek farklı polimerlere eklemektir. Bu çalışmanın amacı atık EPDM tozlarının, polipropilen EPDM karışımlarının bükülme özellikleri üzerindeki

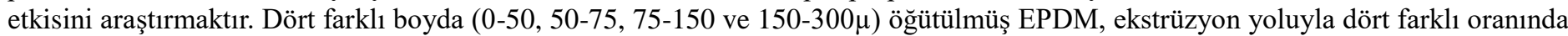
$\%$ 0, \% 10, \% 20, \% 30 ve \% 50 ile polipropilene eklendi. Bu karışımlara ayrıca \% 1 oranında kaydırıcı ve \% 0.2 oranında antioksidan ilave edildi. Test numuneleri bu karışımlardan enjeksiyonlu kalıplama ile hazırlandı. Standartlara göre hazırlanan numunelere eğilme ve HDT testi yapildi.

Anahtar Kelimeler: EPDM (etilen porpilen dien monomeri), karışım, eğilme özellikleri.

\section{Effect of Addition of Recycled EPDM Size on The Bending Properties of Polypropylene}

\begin{abstract}
EPDM (ethylene propylene diene monomer) is an important synthetic rubber and is used in significant quantities in many different sectors. In parallel with the increase in the amount of usage, EPDM waste is emerging. Such materials do not have the possibility of being melted and processed again due to their cross-linking. EPDM waste is usually consumed in the form of fuel, which is already a significant loss for the import-based plastic industry. Another method of evaluation of EPDM residues is to add them to different polymers by bringing them into small dimensions. The aim of this study is to investigate the effect of waste EPDM powders on the bending properties of polypropylene EPDM mixtures. Ground EPDM (GEPDM) with four different sizes (0-50, 50-75, 75-150 and $150-300 \mu$ ) were added to polypropylene with four different weight ratios $0 \% 10 \%, 20 \%, 30 \%$ and $50 \%$ via extrusion method. These mixtures were also added with a $1 \%$ slider and $0.2 \%$ antioxidant. Test samples were prepared by injection molding from these mixtures. Bending and HDT tests were performed on the samples prepared according to the standards.
\end{abstract}

Keywords: EPDM (ethylene propylene diene monomer), mixture, bending properties.

\footnotetext{
* Sorumlu Yazar: Marmara Üniversitesi, Teknoloji Fakültesi, Metalurji ve Malzeme Mühendisliği Bölümü, İstanbul, Türkiye, ORCID:0000-00019677-477X, ilyaskartal@marmara.edu.tr
} 


\section{Giriş}

Kauçuklar diğer adıyla elastomerler dış kuvvetlerinden dolayı geri dönüşümlü deformasyon yetenekleri ile karakterize edilen polimerik malzemelerdir. Onların deformasyon hızı, deforme olmuş kauçuğun yapısına ve molar kütlesine ve deformasyonun dış koşullarına bağlıdır. Elastik ve/veya hiper elastik deformasyon olarak adlandırılan bu özellikler kauçuk makromoleküllerinin, polimer zincirinin atomları arasındaki veya kimyasal bağların deformasyonu olmadan deforme kuvvetlerinin etkisi altında daha organize bir durum oluşturma kabiliyetinden kaynaklanır (Vahapoğlu ve ark. 2006, Bismarck ve ark. 2006).

Kauçuklar en çok vulkanize edilmiş formda kullanılır. Bu forma vulkanizasyon ile getirilebilirler. Bu işlem, malzemeye benzersiz özellikler kazandıran, bir uzaysal vulkanizat ağına yol açan kauçuk makromoleküller arasında kimyasal ve fiziksel enine bağların oluşturulmasına dayanır. Vulkanizasyon işleminde uygun fonksiyonel kauçuk grupları ile reaksiyona girebilen kauçuk makromolekülleri (örneğin, kükürt, peroksitler, metal oksitler, reçineler, kinonlar ve diğerleri) arasında kimyasal çapraz bağlar oluşturmak için çeşitli kimyasal - vulkanize edici maddeler kullanılır (Wolcott 1996, Aşık 1997).

Kauçuk grubunun en önemli polimerlerinden biri de EPDM'dir. EPDM, etilen ve propilenin kopolimerizasyonu ile üretilen bir polimerdir. Reaksiyonda çift bağ yoktur, yani tamamen doymuş bir yapıdır. Bu yapı, kopolimerlerin ozon ve oksijene karşı mükemmel dayanıklılık göstermesini sağlar. Ancak diğer polimerlerle karıştırılma imkanı yoktur. Peroksit ve radyasyon dışında vulkanize edilemezler (Geng 2004).

EPDM kimyasal yapısı gereği sıcaklığa, havaya, ozona, ışığa, oksidasyona ve suya mükemmel direnç gösterir. Sülfür ile vulkanize edilmiş EPDM kauçuklarında uygun sülfür hızlandırıcının seçilerek $120^{\circ} \mathrm{C}$ 'ye kadar ısıl yaşlanma direnci ve maksimum kullanım sıcaklığı elde edilebilir. Benzer şekilde peroksit karışımı seçilerek $150{ }^{\circ} \mathrm{C}$ 'ye kadar ssıl direnç ve maksimum kullanım sıcaklığı elde edilebilir. Metallere yapışabilme özelliği çok iyi olmamakla birlikte, mükemmel elektrik yalıtımı, $-50{ }^{\circ} \mathrm{C}$ 'ye düşük sıcaklık dayanımı vardır. Yüksek dolgu ve yağ alabilme özelliğinden dolayı düşük maliyette karışımlar oluştururlar. Sulu ve konsantre asit ve alkalilere dayanıklılık gösterirler. Düşük yoğunluklu oldukları için hafif malzemeler üretmek mümkündür. Ayrıca iyi sayılabilecek kopma mukavemeti, aşınma direnci ve yırtılma direnci vardır. Ancak yağa karşı direnci ve alev direnci oldukça sınırlıdır. EPDM kauçuğunun mineral, yağ ürünleri, yağlayıcılar, yağlar ve petrol ürünleri ile kullanımı uygun değildir. Özellikle petrol ürünlerine karşı dirençsiz olması onun otomobil uygulamalarında kullanımını sınırlar (Stark 2004, Dhakal ve ark. 2006).

EPDM'in günlük yaşamda kapı ve cam fitili, sünger fitili, radyatör ve 1sıtma hortumları, beyaz eşya körük ve contaları, konveyör kayışları, tank kaplama ve silindir kaplamada kullanılmakla birlikte hayatımızın bir çok alanında uygulamaları mevcuttur (Törmala ve ark. 1985, Gastedt ve ark. 2007).

Kauçuk esaslı malzemeler malzemeler çapraz bağlı olmaları nedeniyle termoplastiklerde olduğu gibi tekrar eritilip işlenme imkanına sahip değildirler (Xiao ve ark. 2004). Bununla birlikte, kauçuk türü malzemeler belirli boyutlara getirilerek dolgu olarak kullanılabilmektedir. Termoplastiklerle karışım yapılacaksa karışım öncesi özel bir şekilde ufalanmaları gerekmektedir. Bu tür karışımlarda anahtar nokta kauçuk fazın olabildiğince küçük boyutlara indirilmesidir (Jacob ve Bhowmick (2001).

Doğal veya sentetik kauçukların geri dönüşüme hazırlanmasında oda sıcaklığında kırma ve sıv1 azotla soğutarak kırma olmak üzere iki yöntem kullanılmaktadır. Sıvı azot yönteminde ilk yatırım ve işletme masrafları göreceli yüksek olmakla birlikte oda sıcaklığında kırma işlemine göre daha küçük boyutlu taneler elde edilebilmektedir. Sıvı azotla soğutarak yapılan kırma işleminde kriyojenik olarak adlandırılan düşük sıcaklıkların malzemeler üzerindeki gevrekleştirici etkisinden faydalanılmaktadır. Oda sıcaklığında yapılan kırma işleminde kauçuk malzemelerin rijit olmamaları yani olabildiğince elastik özellik sergilemeleri dolayısıyla sıv1 azot yönteminde elde edilen küçük boyutlar bu yöntemde mümkün olmamaktadır. Sıvı azot yönteminde birkaç mikronluk tane boyutları mümkünken oda sıcaklığı yönteminde etkin olarak 100 mikronluk boyutlara inilebilmektedir (Çetin 2009). Dolayısıyla kırma yönteminin belirlenmesinde elde edilmesi düşünülen nihai ürün belirleyici olmaktadır. Bazı uygulamaları için oda sıcaklığında yapılan öğütme yeterli olurken, bazı uygulamalar için mutlaka sıvı azotla soğutma sonrası öğütme gerekli olmaktadır.

Kompozitlere ilave edilen dolguların boyutlarının etkisi üzerine birçok çalışma yapılmıştır (Homkhiew ve ark. 2018, Charoenwong 2016, Khodabandelou ve ark. 2015). Dolguların boyutlarının değişimiyla mekanik özelliklere etkisinin de değiştiği bilinmektedir. Bu çalışmada da EPDM dolgusnun boyut etkisi incelenmiştir. Bunun için oda sıcaklı̆̆ında öğütme yöntemi tercih edilmiştir. Ancak özel çeneleri bulunan bir öğütme sistemi yerine bir taş motoruna bağlanmış disk şeklindeki tel firçanın aşındırıcı etkisinden faydalanılmaya çalışılmıştır. Elde edilen malzeme çok küçük tanecikleri de içeren geniş bir boyut dağılımına sahiptir. Bu malzeme elenmek suretiyle aşırı büyük tanelerden arındırılabildiği gibi farklı boyutlara da ayrıştırılabilir.

$\mathrm{Bu}$ çalışmanın amacı, önceden kür edilmiş belirli bir toz boyutlarına sahip EPDM kauçuğunun polipropilen ile karıştırılmasıdır. Elde edilen karışım sayesinde, bir taraftan atık EPDM değerlendirilirken diğer taraftan tokluğu daha yüksek bir plastik malzeme karışımı elde edilebilecektir. Bu çalışmada PP+öğütülmüş EPDM karışımı granüllerden enjeksiyon yöntemiyle deney numuneleri hazırlanarak eğilme ve HDT testine tabi tutuldu.

\section{Materyal ve Metot}




\subsection{Malzemeler}

Bu çalışmada polimer matris olarak İzotaktik yapılı PETKIM'in PETOPLEN ticari isimli PP MH418 kodlu polimeri kullanıldı. Çalışmada kullanılan EPDM kauçuğu Düzce'de Standart Profil Firması tarafından yaklaşık 15 mm kalınlığında plakalar halinde üretildi. Söz konusu EPDM kauçuğu Standart Profil Firmasının, taşıt araçlarının kapı fitillerinin üretiminde kullandığı malzemenin aynısı olup siyah renge sahiptir. Standart Profil Firmasının kullandığı EPDM kauçuğu Royalene 525 ticari ismi ile piyasaya sunulan bir malzemedir. İşlemeyi kolaylaştırmak maksadı ile Innospec Leuna firmasının üretmiş olduğu OX.PE WAX LE 262 kodlu polietilen vaks ERAL Türkiye firmasından temin edilip kullanıldı. Gerek ekstrüderde karışım sırasında gerekse enjeksiyon safhasında olası bir oksidasyon etkisini olabildiğince azaltmak maksadı ile Ciba Geigy firmasının üretmiş olduğu IRGANOX 1010 kodlu antioksidant Ciba Türkiye Temsilciliğinden temin edilip kullanıldı.

\subsubsection{Numunelerin hazırlanmast}

Bu çalışmada Standart Profil Firması tarafından yaklaşık 15 mm kalınlığında 30X40 cm ebatlarında özel olarak üretilen plakalar kullanıldı. Bu plakalar aslında otomotiv sektöründe kapı fitilleri imalatında kullanılan EPDM formülasyonuyla aynı kür koşulları altında üretildi. Plaka halindeki bu malzeme $40 \mathrm{~mm}$ genişliğinde şeritler halinde dilimlendi. Bu şeritler öğütme sistemine itme usulü sokularak yüzeylerine taşlama motoruna bağlı döner bir tel firça sürtülmek suretiyle ince partiküller elde edildi.

$\mathrm{Bu}$ toz üretim metodunun doğal bir sonucu olarak toz partikülleri oldukça farklı boyutlarda ortaya çıktı. Işık mikroskobundan elde edilen fotograflardan görüldügü üzere küçük boyutlu partiküller mevcut olmakla birlikte daha büyük boyutlu partiküller çoğunluğu oluşturmaktadır. Buna ilaveten; toz haline getirilmiş EPDM malzemenin elektrostatik etkilerle topaklanma eğilimi nedeniyle partiküller olduğundan çok büyük boyutlarda gözükmektedir. EPDM partiküllerinin 1şık mikroskobundan elde edilen tipik görüntüleri şekil 1'de verildi.

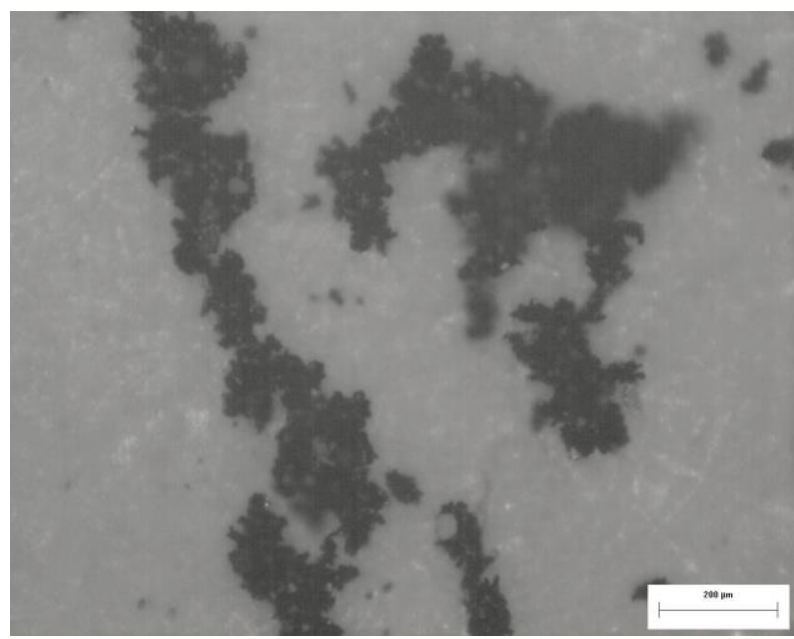

Şekil 1. EPDM Partiküllerinin Işık Mikroskobundan Elde Edilen Tipik Görüntüleri

Öğütülmüş olan bu malzeme daha sonra özel eleklerden geçirilmek suretiyle sınıflandırıldı. Bu çalışmada 0-50, 50-75, 75-150 ve 150-300 mikron boyutlarına sahip öğütülmüş EPDM tozları kullanıldı. Bu tozlara ait bir fotoğraf şekil 2'de görülmektedir. Toz halindeki EPDM, nem alma riskine karşı kullanım anına kadar sıkı kapaklı cam kavanozlar içerisinde saklandı.

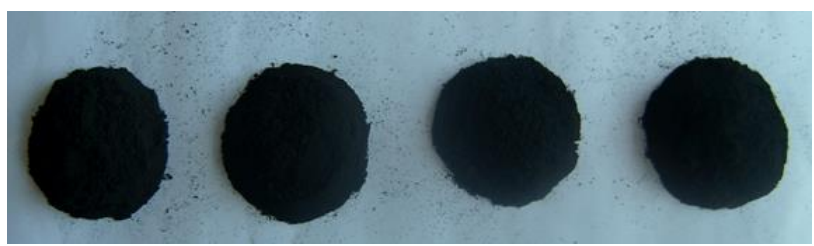

Şekil 2. Özel eleklerden geçirilerek sinfflandırılan EPDM Partikülleri

Karışım hazırlanmadan hemen önce hava sirkülasyonlu bir kurutma firınında ÖEPDM 100 oC'de 2 saat kurutuldu. PP matrise ağırlıkça \%10, 20, 30 ve 50 oranlarında ÖEPDM ilave edildi. Bu karışımlara ayrıca \% 1 oranında kaydırıcı ve \% 0.2 oranında antioksidan ilave edildi. Standartlara göre hazırlanan numunelere eğilme ve HDT testi yapıldı. Eğilme testi ZWICK marka Z010 model çekme cihazı kullanılarak ISO 178 standardına göre ve HDT testi CEAST marka cihaz kullanılarak ISO 307 standardına göre gerçekleştirildi. 


\begin{tabular}{|l|l|}
\hline Parametreler & Değer \\
\hline Enjeksiyon Sıcaklığı ${ }^{\circ} \mathrm{C}$ & $190-210$ \\
\hline Enjeksiyon Basıncı (bar) & $800-1000$ \\
\hline Kalıpta Bekleme Süresi (sn) & 25 \\
\hline
\end{tabular}

\section{Araştırma Sonuçları ve Tartışma}

Bu çalışmada, polipropilen matrise belirli bir boyuta sahip öğütülmüş EPDM kauçuğu dolgu malzemesi olarak ilave edildi ve elde edilen karışımın eğilme özellikleri incelendi.

PP/ÖEPDM karışımlarının eğilmede maksimum mukavemet değerleri şekil 3'de verilmiştir. PP ile öğütülmüş EPDM karışımlarının eğilme özellikleri incelendiğinde ÖEPDM oranının artmasıyla maksimum eğilme mukavemeti azalmıştır. ÖEPDM boyutları arttıkça mukavemet değeri beklenildiği gibi düşmüştür.

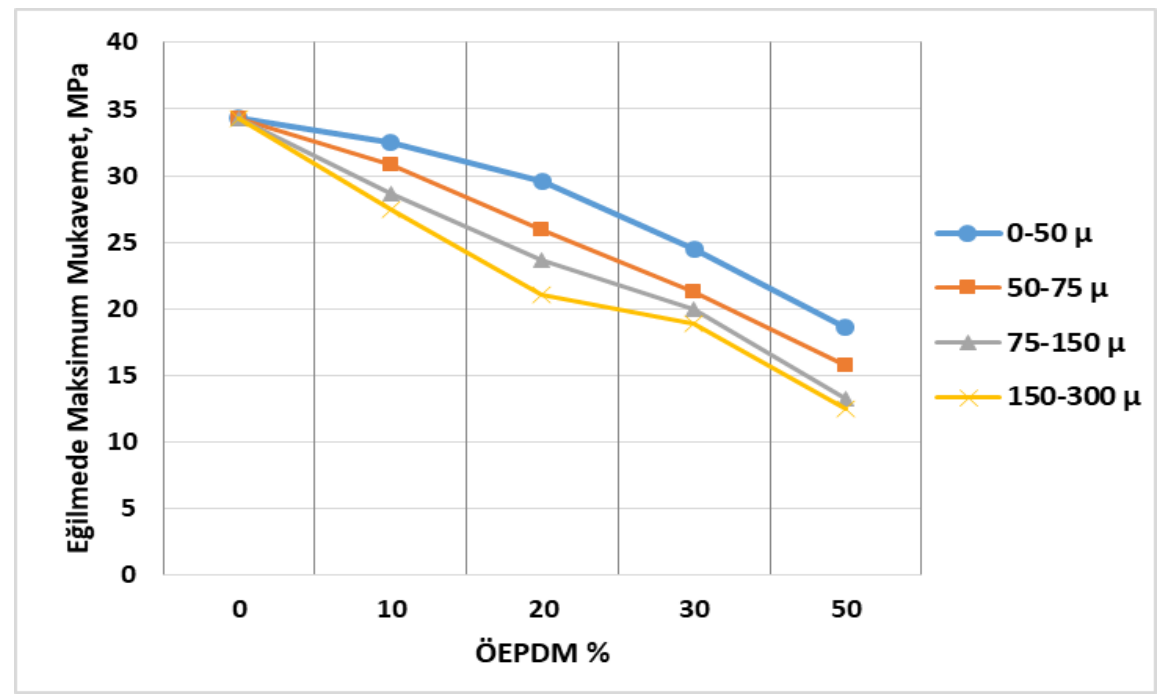

Şekil 3. PP/ÖEPDM karışımlarının eğilmede maksimum mukavemet değerleri

PP/ÖEPDM karışımlarının eğilme modül değerleri şekil 4'te verilmiştir. ÖEPDM ilavesi ile PP kompozitinin modül değerinde düşme görülmüştür. EPDM boyutunun artmasıyla modül değerinde azalma olmuştur.

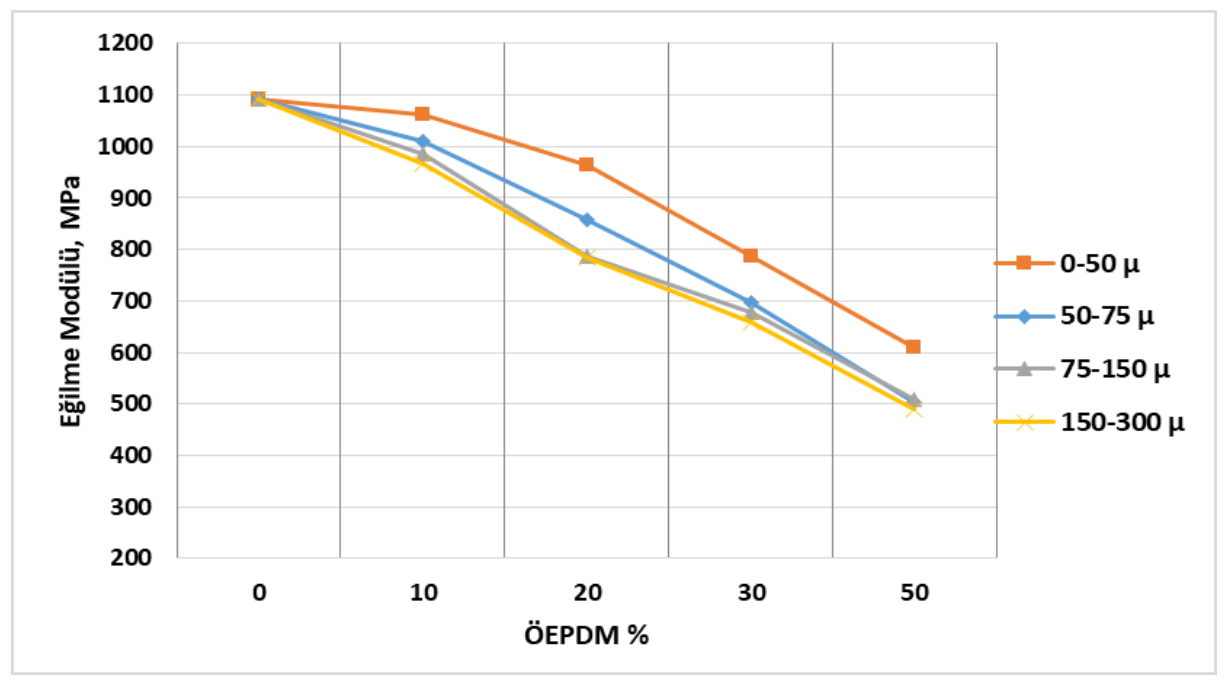

Şekil 4. PP/ÖEPDM karışımlarının eğilme modül değerleri

PP/ÖEPDM karışımlarının maksimum mukavemette \% uzama değerleri şekil 5 ’te verilmiştir. \% uzama miktarı ÖEPDM miktarının artması ile yaklaşık olarak \% 50 oranında artmıştır. EPDM boyutu 0-50 mikron boyutunda olan numunede \% uzama bir miktar artmış, sonra da nerdeyse sabit kalmıştır. 


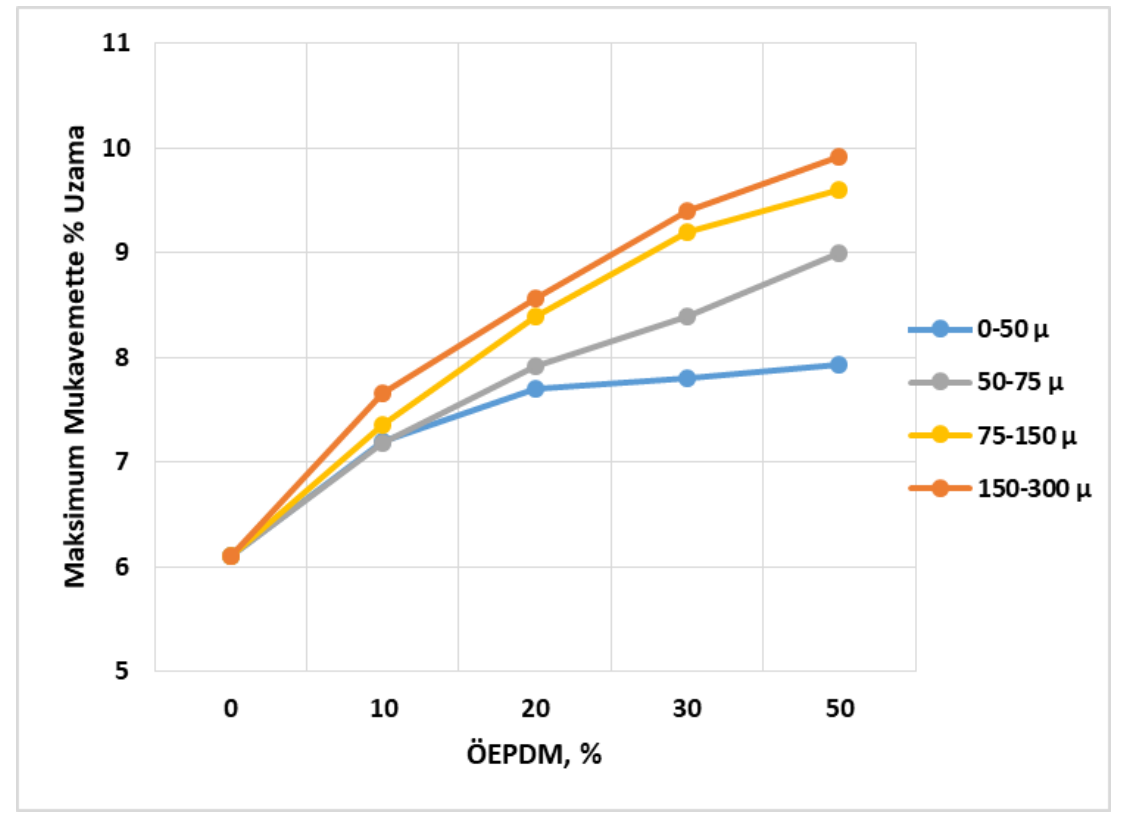

Şekil 5. PP/ÖEPDM karışımlarının maksimum mukavemette \% uzama değerleri

Şekil 6'da PP/ÖEPDM karışımlarının HDT testi sonuçları verilmiştir. PP/ÖEPDM karışımlarının HDT değerleri incelendiğinde ÖEPDM oranının artmasıyla HDT değerlerinin azaldığı, boyutun artmasıyla bu azalmanın kısmi olarak da olsa daha da düştüğü gözlemlendi.

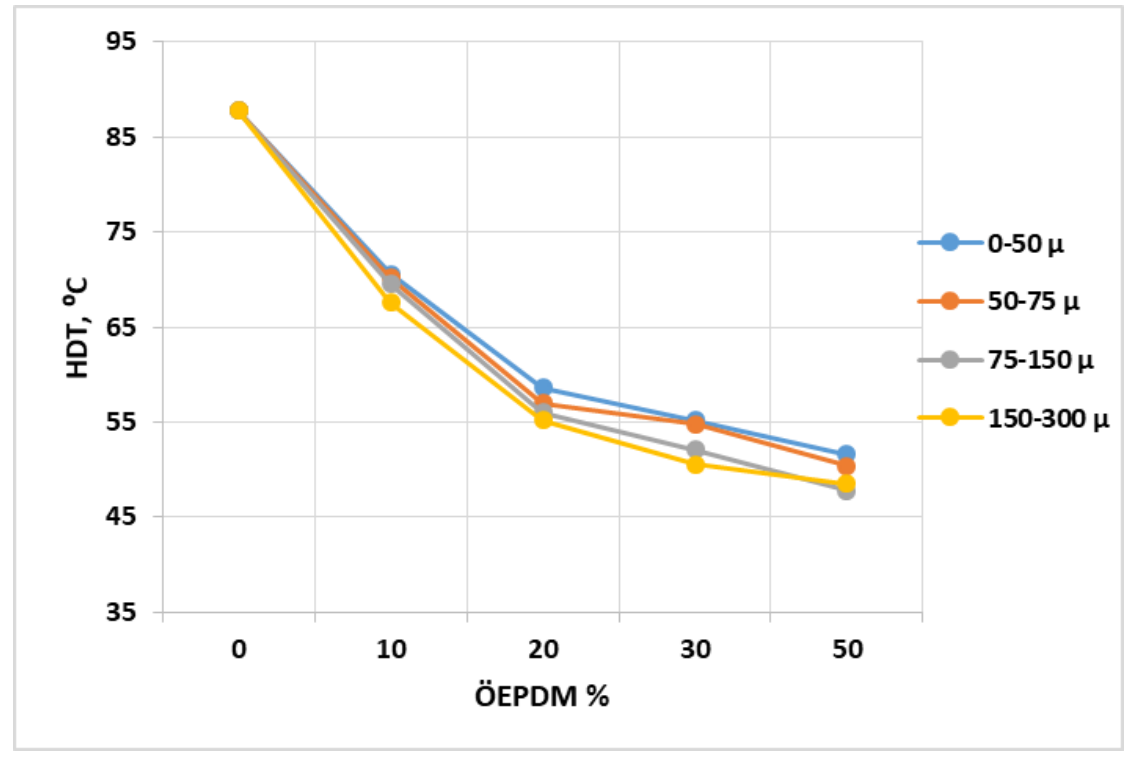

Şekil 6. PP/ÖEPDM karışımlarının HDT testi sonuçları

\section{Sonuç}

EPDM farklı alan ve sektörlerde yoğun kullanıma sahip polimerlerden biri olup kullanım sonrası ciddi miktarlarda EPDM atığı ortaya çıkmaktadır. EPDM gibi polimerler çapraz bağlı yapıları sebebiyle eritilip tekrar işlenme imkânı olmadığından ya yakıt olarak tüketilmekte ya da çok küçük boyutlara getirilmesiyle karışımlara ilave edilmektedir.

EPDM kauçuğunun geri dönüşümde ögütülerek polipropilene ilave edilmesi beklenildiği gibi polipropilen matrisli karışımların eğilme rijitliğini düşürmüştür. Karışıma ilave edilen miktar arttıkça mukavemet değerleri düşmüştür. \% 50 EPDM tozu ilave edildiğinde polipropilenin eğilme özellikleri de \% 50 oranında düşmüştür. Fakat bu düşüş boyut değişimi ile değişiklik göstermiştir. ÖEPDM toz boyutu azalmasıyla bu düşüş daha az olmuştur. Dolayısı ile bu mukavemet değerleri, kabul edilebilir durumlarda olduğunda atık EPDM'in geri dönüşüm malzemesi olarak kullanılabileceği sonucuna varıldı. 


\section{Kaynakça}

Vahapoğlu V., Yüksel H. T. (2006). EPDM Sentetik Kauçuğu, Proceddings of 11th International Materials Symposium, Denizli, April 19-21333-337.

Bismarck A., Baltazar-Y-jimenay A., Sarlkakis K., (2006). Green Composites on Panacea Socio-economic aspects of green materials. Environment, development and sustainability 8 (3), 445-463

Wolcott, M. P.: (1996) Proceedings of the 30th Washington State University International Particleboard/Composites Materials Symposium, J. Appl. Polym. Sci., Pullman, WA; 37

Aşık, M., (1997). Fındıkkabuklarının Değerlendirilmesi, Doktora Tezi İTÜ Kimya Müh. Böl., İstanbul

Geng, Y.; Li, K.; Simonsen, J.: (2004) Effects of a Compatibilizer System on the Flexural Properties of Wood-Polyethylene Composites, J. Appl. Polym. Sci., 91 3667-3672

Stark NM, Matuana LM, Clemons CM. (2004) Effect of processing method on surface and weathering characteristics of woodflour/HDPE composites. J Appl Polym Sci; 93, 1021-1030.

Dhakal, H.N., Zhang, Z.Y., Richardson, M.O.W., (2006). Effect of water absorption on the mechanical properties of hemp fibre reinforced unsaturated polyester composites, Composites Science and Technology, doi.org/10.1016/j.compscitech.2006.06.019

Törmälä, P., Pääkkonen and Luoto, K., (1985). Injection molding and extrusion of composites of low-density polyethylene and plywood grindings, Journal of Applied Polymer Science, 30, 423-427.

Gamstedt EK, Nygård P, Lindström M. (2007). Transfer of knowledge from papermaking to manufacture of composite materials. In: Proceedings of the 3rd wood fibre polymer composites international symposium, Bordeaux, $12 \mathrm{p}$.

Xiao W. H., Huang S. O., Tao J.; (2004). Morphology Rheology and Mechanical Properties of Dynamically Cured EPDM/PP Blend: Effect of Curing Agent Dose Variation",Journal of Applied Polymer Science Vol. 92, 357-362.

Jacob C., (2001). Bhowmick S.; Reycling of EPDM Waste. II. Replacement of Virgin Rubber by Ground EPDM Vulcanizate in EPDM/PP Thermoplastic Elastomerik Composition, Journal of Applied Polymer Science Vol.82,: 3304-3312.

Çetin, C.; (2009). Lastik, Kauçuk, Poliüretan Geri Dönüşüm Teknolojisi, Kauçuk Derneği Dergisi Sayı: 35, 28-29.

Homkhiew C., Rawangwong S., Boonchouytan W., Ratanawilai T.; (2018) Composites from Thermoplastic Natural Rubber Reinforced Rubberwood Sawdust: Effects of Sawdust Size and Content on Thermal, Physical, and Mechanical Properties, International Journal of Polymer Science 2018(3):1-11

Charoenwong C., (2016) Effect of adhesives and particle sizes on properties of composite materials from sawdust, Proceedings of the 7th IMT-GT UNINET and the 3rd International PSU-UNS Conferences on Bioscience, page 108-121

Khodabandelou M., Aghjeh M.K.R.; (2015) Impact behavior of CNT-filled PP/EPDM blends: effect of dynamic vulcanization and PP-g-MA compatibilizer, Polym. Bull. DOI 10.1007/s00289-015-1566-2 